\title{
A QUESTÃO DA EXPERIÊNCIA NO ENSINO DA FILOSOFIA: UM PROBLEMA CONTEMPORÂNEO
}

\author{
Rodrigo Pelloso Gelamo*
}

RESUMO: Os problemas que afetam a sociedade não estão mais centrados no âmbito da reflexão sobre a cultura, a política e em uma inflexão a si mesmos. A vida, um dos principais elementos da reflexão filosófica, tornou-se destituída de valor e passou a ser medida pelo "desejo" do mercado. Por isso, segundo Foucault, é difícil criar condições de resistência, uma vez que não se sabe de onde vem o poder, onde estamos e qual o nosso desejo: tudo o que pertencia ao sujeito está capturado pelo biopoder. Assim, vivemos (sobrevivemos, nos termos de Agamben) num momento de empobrecimento da experiência, da vida, dos valores e de nós mesmos. O problema que se coloca é, então, como resistir a esse empobrecimento? Pensamos que uma possível chave para pensar esse problema esteja na procura por compreender como nos tornamos empobrecidos dessa capacidade de fazer experiência. Nossa intenção é compreender como o ensino da filosofia se posiciona face à pobreza de experiência, apontada por Benjamin.

Palavras-chave: Ensino da Filosofia; Experiência; Transmissão do Conhecimento.

\section{THE MATTER OF EXPERIENCE IN THE TEACHING OF PHILOSOPHY:} \section{A CONTEMPORARY PROBLEM}

ABSTRACT: The problems that affect society are no longer focused on the scope of reflection about culture, politics and on a turnaround in itself. Life, one of the main elements of philosophical reflection, has become devoid of value and now is measured by the "desire" of the market. Hence, according to Foucault, it is difficult to create conditions of resistance, since it is not known where power comes from, where we are and what we want: everything that belonged to the subject is captured by biopower. Thus, we live (survive, according to the terms used by Agamben) at a time of impoverishment from culture, life, values and ourselves. The problem that arises, then, is how to resist to that impoverishment? We believe that a possible key to think this problem is the attempt to understand how we have become impoverished from that capacity to do an experience. Our intention is to comprehend how the teaching of philosophy faces the poverty of experience, pointed by Benjamin.

Keywords: The Teaching of Philosophy; Culture; Experience; Transmission of Knowledge.

* Doutor em Educação pelo Programa de Pós-Graduação em Educação da Faculdade de Filosofia e Ciências da Universidade Estadual Paulista Júlio de Mesquita Filho (UNESP); Professor do Departamento de Didática e do Programa de Pós-Graduação em Educação da Faculdade de Filosofia e Ciências da Universidade Estadual Paulista Júlio de Mesquita Filho (UNESP). E-mail: gelamo@gmail.com 


\section{Introdução}

Nossa intenção no presente texto é entender de que modo podemos diagnosticar um problema que pensamos ser central na discussão atual sobre a cultura e a política: a experiência. Quando pensamos em cultura, sempre nos deparamos com o debate sobre os bens produzidos e eternizados pela humanidade, pelas maneiras como cada indivíduo se apropria (objetivamente), participa (subjetivamente), se insere (ou é tomado) nesses (por esses) bens humanos. Quando falamos em política vinculada à cultura ou em política cultural, pensamos em ações que visam à manutenção, ao fortalecimento, à divulgação da mesma e à instauração de mecanismos que insiram/submetam o homem a ela. No meio disso tudo está o indivíduo, que sofre a ação política, cujo objetivo é sua integração no contexto cultural no qual vive.

As políticas culturais sempre foram objeto de preocupação do mundo civilizado e perpassam os escritos religiosos, como a Bíblia e o Alcorão; poético-literários, como a Ilíada e a Odisséia; a filosofia, com a discussão sobre a Paideia e a formação filosófica no preparo do homem para a polis em Platão, etc. O objetivo dessas mais variadas maneiras de discurso é a criação de modos de formação cultural do indivíduo e de sua integração na sociedade. Nesse sentido, a discussão sobre a formação sempre foi alvo de teorias e de ações políticas de formação do homem. Com o advento das escolas, nos séculos XVII e XVIII, notamos uma mudança na política cultural que se seguiu. Nesse contexto, a instituição educacional passou a assumir lugar de destaque nas políticas educacionais, com maior responsabilidade pela inserção do indivíduo na sociedade e por sua formação cultural.

A essa política cultural pode ser dado o nome, de forma geral e tradicionalmente, de formação do sujeito, cujo correlato contemporâneo é a educação. Apesar de encontrarmos no conceito de formação uma abrangência maior do que no de educação (e muito maior do que no de educação escolar), de certo modo, foi atribuída à instituição escolar a função de formar, educar e de ensinar o homem. Assim, ainda pensando em termos contemporâneos, o efetivo exercício de educar se dá pelo ensino. 


\section{0 ensino da filosofia no contexto do iluminismo:}

\section{Kant e Hegel}

Kant, em suas notas de aula publicadas sob o título de Sobre a pedagogia (1995), já chamava a atenção para a necessidade de o homem ser educado. Para ele, o homem é o único animal, ou criatura, que precisa ser educado. Ao contrário dos outros animais, que aprendem por imitação, o homem precisa de cuidados especiais que seriam indispensáveis, uma vez que precisa aprender, entre outras funções importantes, a conviver em sociedade, a se disciplinar e a entrar no mundo cultural ao qual pertence a humanidade.

Nesse contexto, para Kant (1995), a disciplinarização do sujeito tem uma função muito específica, qual seja: a de transformar aquilo que é "animal" ou selvagem no homem em humano e, além disso, potencializar aquilo que lhe é natural: a disposição ao pensamento e ao aprendizado. $\mathrm{O}$ sentido de humanização é aqui empregado porque a disciplina tem a função de possibilitar que o homem possa domesticar em si mesmo algo que lhe é próprio e transformar isso em socialização. A disciplina teria a função de direcionar a predisposição humana e afastar o educando das tendências indesejáveis. Assim, nas palavras de Kant, "A disciplina submete o homem às leis da humanidade e começa a fazê-lo sentir a força das próprias leis" (KANT, 1995, p. 12-13).

Por outro lado, para Kant, a formação cultural do homem não está apenas no exercício de instrução e disciplina, fato que o tornaria apenas um submisso. Para que tenha condições de usar sua liberdade e autonomia, para tornar-se um Aufklärer e abandonar seu estado de menoridade (KANT, 1985), o homem não pode ser apenas um instruído, uma vez que, "Preceitos e fórmulas, estes instrumentos mecânicos do uso racional, ou, antes, do abuso, de seus dons naturais, são os grilhões de uma perpétua menoridade" (KANT, 1985, p. 102). Assim, o que afastaria o homem da menoridade e, consequentemente, torná-lo-ia esclarecido, seria o próprio bom uso da razão, que se dá na preparação crítica do sujeito, fundada no aprendizado do uso da razão, única capaz de possibilitar ao homem a humanização, a qual, nesse contexto, poderia ser entendida como um meio de sua inserção na cultura. Apesar de Kant (1985) considerar que apenas o homem, por ele mesmo, é quem poderia sair do seu estado de menoridade, de não esclarecimento, ele imputa à instituição formativa a 
responsabilidade para se atingir esse fim. Nesse contexto, a filosofia tem papel central no processo formativo, pois ela é capaz de formar o homem moral e culturalmente, promovendo-o de seu estado natural de menoridade para um estado de autonomia, cujo resultado é o homem capaz de se emancipar culturalmente.

Hegel, assim como Kant, apesar de toda a polêmica entre eles em relação aos modos de entendimento de como a filosofia exerceria seu papel na formação cultural do homem e de como ela deveria ser ensinada, também a coloca como a principal provedora de cultura para o homem em seu processo formativo. No entanto, enquanto esse processo formativo, em Kant, estaria centrado na crítica da razão, no caso de Hegel (para quem não só a filosofia exerceria esse papel), estaria centrado no ingresso na cultura superior. Assim, outras disciplinas, tais como as teorias do direito, da moral, da religião, as ciências de conteúdo pleno, como a Lógica, as de conhecimento do humano, como a psicologia, que compunham a educação universitária, também seriam de fundamental importância por tratarem de temas importantes à formação cultural do homem, porém não poderiam substituir a filosofia. Na concepção de Hegel, a filosofia é a mãe de todas as ciências. Desse modo, ela seria a responsável por avaliar e legitimar o conhecimento adquirido pelas outras ciências, uma vez que seu papel seria a busca de conhecimentos absolutos da verdade.

Nesse sentido, Hegel indica que a disciplina de Filosofia seria a base mais importante na formação cultural do homem e seu ensino deveria se dar desde o ginásio, assumindo seu papel central na universidade. Nessa preparação, a Filosofia teria um lugar privilegiado, porque, para Hegel,

[...] a filosofia contém os mais elevados pensamentos racionais acerca dos objetos essenciais, contém o que há de universal e verdadeiro nos mesmos; é importante familiarizar-se com esse conteúdo e dar lugar na mente a estes pensamentos. $\mathrm{O}$ modo triste de proceder, meramente formal, este buscar perenes, o raciocinar ou especular assistemáticos tem como consequência a aquisição de conteúdos vazios, o vazio intelectual das mentes, contra o que elas nada possam. (HEGEL, 1991, p. 139-140).

Neste sentido, o ensino da filosofia do ginásio à universidade seria a maneira de possibilitar às pessoas o acesso à cultura, uma vez que esta, na concepção de Hegel, seria o caminho para se compreender e se 
integrar no devir da história e atingir o espírito absoluto. Isso porque, para ele, a filosofia tem um papel superior e fundamental para a compreensão e fundamentação de todas as ciências, bem como para o entendimento da cultura da humanidade. Assim, a formação cultural (Bildung) configurarse-ia na aprendizagem filosófica, juntamente com a arte e com a religião, como o último estágio da formação do homem.

A possibilidade aberta pela filosofia de Kant indica ser necessário formar o homem para ser crítico da cultura, mas seria preciso que ele obedecesse (criticamente) às normas da ordem civil. Hegel, por outro lado, pretendia que, por meio da filosofia, o homem se inserisse na cultura superior e, assim, houvesse uma conciliação por meio da subordinação, da hierarquia dos saberes e pelo ingresso no espírito objetivo do tempo. Em ambos os casos, a filosofia e seu ensino (tanto do filosofar kantiano quanto da história da filosofia de Hegel) seria o modo de propiciar ao homem a cultura, fosse pela crítica (Kant) ou pelo ingresso em seu devir da história (Hegel).

\section{0 declínio da filosofia, 0 empobrecimento da cultura como bem e a imitação como valor}

Nesse contexto, surge a ideia de que a verdadeira formação cultural só poderia ser dada pela filosofia como uma forma crítica de ingresso na cultura. Até nossos dias, notamos reverberar essa mesma forma de pensamento. Apesar de todo o esforço feito pelos filósofos para legitimar a filosofia como provedora, formadora e tantos outros atributos que poderíamos nela encontrar, contemporaneamente, notamos o seu declínio como bem cultural e como política de formação do homem¹.

Esse declínio da cultura filosófica não aparece apenas como problema só na (ou da) filosofia ${ }^{2}$. Notamos também uma banalização da cultura pela humanidade de forma geral. Mesmo quando o foco de análise da cultura não é feito desde um ponto de vista filosófico - mas como o modo de vida de um povo, de uma tribo, de uma família, etc. -, notamos a mesma banalização encontrada na cultura filosófica.

A cultura que se foi particularizando nos modos de vida de um povo no decorrer da história foi sendo gradativamente substituída por modos de existência que lhe eram externos. Quase como uma repetição 
do que ocorreu na época das colonizações, quando, no caso do Brasil, o modo de existência dos nativos foi deles expropriado e lhes foram introjetados a cultura, a língua, a religião e os costumes portugueses, parecenos que o mesmo acontece conosco na contemporaneidade, mas de forma muito mais passiva que aquela das colonizações.

Com o advento das políticas de globalização estão se retirando das pessoas seus vínculos culturais, os quais serviam como princípio norteador de seus valores e crenças e propiciavam que aqueles que viviam em uma mesma região se reconhecessem como comunidade e como pertencentes a uma mesma cultura, enfim, reconhecessem a si mesmos como elementos de um povo (fosse de uma nação ou de uma tribo). E, com o declínio da filosofia, não se tem encontrado suporte para fazer uma crítica (Kant) ou para se resgatar a teleologia da história (Hegel).

Os problemas globalizados que afetam a sociedade não estão mais centrados no âmbito da reflexão sobre a cultura, seja aquela entendida como um bem cultural da humanidade, aquela própria a um povo, ou ainda sobre a cultura de si mesmo, mas em uma cultura do estar na moda e em uma cultura marcada pela política econômica, uma política de guerra em que a cultura é esquecida. O ser humano, nessa relação de poder, torna-se algo desprovido de importância em si mesmo e passa a ser apenas um elemento na relação e no uso do poder. A vida destituiu-se de todo valor e passou a ser medida pelo "desejo" do mercado, ou seja, pela cultura do mercado. Para usar as palavras de Pelbart (2007), nossa existência foi reduzida a um mínimo biológico. A vida plena de atributos, a vida entendida como modo de vida, cujo termo grego é bíos - bios politikós, biós theoretikós e assim sucessivamente - deixou de existir e passamos à condição de zoé, ou seja, a vida destituída de atributos, vida meramente biológica e, portanto, sem distinção da "vida" própria aos animais.

Segundo Pelbart (2007),

O contexto contemporâneo se caracteriza por uma nova relação entre o poder e a vida. Por um lado, uma tendência que poderia ser formulada como segue: o poder tomou de assalto a vida. Isto é, ele penetrou todas as esferas da existência, e as mobilizou inteiramente, pondo-as para trabalhar. Desde os genes, o corpo, a afetividade, o psiquismo, até a inteligência, a imaginação, a criatividade, tudo isso foi violado, invadido, colonizado, quando não diretamente expropriado pelos poderes. (PELBART, 2007, on-line) 
Tal poder, do qual fala Pelbart e, para fazer uma referência a Foucault, não visa a destruir a vida (zoê), mas a dominá-la, ou seja, dentro desse estado de dominação da vida, o objetivo do poder é potencializá-la, conduzi-la, aprimorá-la. Nessa estratégia de dominação da vida pelo poder surge um problema, uma vez que, ao mesmo tempo em que o poder busca a manutenção da vida (zoe) , captura a vida do sujeito (bíos), captura a instância do desejo e a toma de assalto. Por isso, segundo Pelbart, é difícil criar condições de resistência ao poder, uma vez que não se sabe de onde ele vem, onde estamos e qual o nosso desejo, pois tudo o que pertencia ao sujeito está capturado pelo biopoder. Assim, não só a acepção de cultura sofreu uma mudança, mas também o desejo foi capturado pelos mecanismos de poder no acesso a essa "cultura".

A vontade de acesso à cultura, principalmente das pessoas nos países em desenvolvimento, como o Brasil, passou a ser a de conhecer o modo de vida dos países europeus (a tradição de modo geral) e norte-americanos (a economia e a cultura de mercado), grandes responsáveis pela enunciação dos valores globais, para imitar esse "estilo de vida" e incorporar seus valores e crenças. Nesse sentido, tornamo-nos duplamente empobrecidos: em nossa cultura particular, uma vez que ela foi, paulatinamente, se desmantelando e em seu lugar foi sendo colocada outra cultura na qual a vida plena (bios) deu lugar a uma vida nua (zoe); e intelectualmente, em nossa capacidade de fazer a crítica a esse empobrecimento, uma vez que o acesso à filosofia nos foi dificultado. Assim, vivemos (ou seria melhor dizer que sobrevivemos?) em um momento de empobrecimento da cultura, da vida, dos valores, enfim, de nós mesmos e passamos a uma vida imitativa (mimesis) de modos de vida sem sentido, cujos valores são a aparência e a ostentação de poder.

Podemos dizer, então, que o empobrecimento da cultura se dá em três sentidos: por um lado, pela deterioração da cultura como um bem da humanidade; por outro, pela imposição das "culturas superiores" e pela subordinação daquelas que são tidas como inferiores (como é o caso da relação entre os Estados Unidos com os países árabes), sem respeito pela pluralidade e pela diferença cultural; e, por último, pela imitação e autossubordinação a outras culturas que são consideradas como melhores por serem guiadas por valores "globais". 


\section{O lugar do conhecimento e o lugar da experiência}

Se pensarmos com Kant e Hegel, a saída para os problemas apontados anteriormente poderia estar no ensino da filosofia, melhor dizendo, em uma educação na qual o ensino da filosofia, ou o ensino do filosofar, fosse privilegiado. No entanto, atualmente a filosofia é tratada com descrédito e seu ensino, como um misto de reforço do senso comum com um palavrório filosófico, que visa apenas ao exercício retórico sedutor do professor, ou ainda, a uma exposição questionável de erudição. Os momentos reservados às aulas tornaram-se um espaço "terapêutico" no qual as pessoas expõem suas opiniões, mas não fundamentam nem elaboram seus pensamentos, fazendo-os ressoar no vazio existencial no qual estamos envolvidos.

Parece que essa problemática ressoa naquela apontada por Benjamim em 1933 e a mantém atual. Para ele, não nos apropriamos mais dos bens culturais da humanidade porque tornamo-nos pobres justamente naquilo que nos possibilitava ter acesso a eles: a experiência. A tese benjaminiana é a de que a pobreza de experiências é a principal responsável por esse empobrecimento cultural. Segundo ele, vivemos em uma nova barbárie, não em uma barbárie particular a um indivíduo, mas a toda a sociedade. Pela falta de experiência e de apropriação dela, colocamo-nos em tal situação.

O problema que se impõe, então, é o de como resistir a esse empobrecimento? Partindo dessa problemática, pensamos que as questões que circunscrevem a experiência precisam ser consideradas de forma mais detida para entendermos de que forma o ensino da filosofia, tido como solução por Kant e Hegel, além de não solucionar o problema, contribui para seu incremento. Parece-nos que a filosofia e seu ensino, de certo modo, tenham colaborado para que os problemas apontados anteriormente se constituíssem, uma vez que também primaram pela destituição da experiência, valorando a transmissão do conhecimento como principal fonte de formação cultural.

O tema da experiência não é um problema novo em filosofia, mas se confunde com sua história. Notamos a presença do debate sobre esse assunto já em Platão e Aristóteles e, a partir deles, todo um conjunto de argumentos e contra-argumentos foi se constituindo. O problema lançado por Platão visa a denunciar a experiência sensível (empeiria) como provedora de conhecimentos que não levavam o cidadão a conhecer as 
verdades acerca das coisas, do mundo e da pólis. Por isso, era considerada por ele como um conhecimento inferior quando comparado àquele obtido pela contemplação das ideias. Para Platão, a experiência possibilitarnos-ia ter acesso ao mundo material, mundo das formas imperfeitas, cuja principal característica é ser mutável e fugidio. Assim, o conhecimento que se fixasse nesse registro teria as mesmas características de seu fundamento - a imperfeição e a mera aparência - e, por esse motivo, poderia ser considerado como uma doxa, isto é, um conjunto de conhecimentos que se pautam em opiniões e estão em constantes mutações devido à particularidade e à fugacidade de seu fundamento. Desse modo, a experiência sensível constitui-se como um problema para o conhecimento verdadeiro, conhecimento este que só poderia encontrar seu verdadeiro fundamento no mundo imutável e perfeito das ideias, cujo acesso se dá por meio da contemplação, e não da experiência. Nesse sentido, a experiência não poderia ser considerada como um modo de filosofar. Aproximando o pensamento platônico de nosso problema, a experiência jamais poderia ser considerada como uma ação válida de acesso à verdadeira cultura, que seria aquela encontrada na imutabilidade do mundo das ideias.

Aristóteles, por outro lado, não é tão radical quanto Platão na recusa à experiência (empeiria). Segundo ele, a experiência é necessária para o conhecimento e funciona como seu pressuposto, mas não é suficiente para que este se constitua. A insuficiência da experiência está na impossibilidade de se traduzir aquilo que foi apreendido por esse mecanismo em algo que seja universal e necessário, uma vez que, pela experiência, só se pode obter pensamentos particulares e contingentes. Nesse sentido, a empeiria (experiência) é inferior à techné (arte), capaz de produzir conhecimentos universais (LARROSA, 2004).

Podemos dizer que esta é a matriz da racionalidade moderna e contemporânea, a qual se estabelece sob a égide da racionalidade para se defender da fugacidade da experiência como conhecimento e como constituidora de cultura. Para Larrosa, "Na origem de nossas formas dominantes de racionalidade, o saber, a linguagem da teoria, a linguagem da ciência, não pode ser nunca a linguagem da experiência" (LARROSA, 2004, p. 22). Essa forma dominante de racionalidade encontra seu auge na modernidade com o advento da ciência moderna, que elimina do sujeito qualquer possibilidade de estabelecer uma relação de significação do e com o mundo por meio da experiência. 
$\mathrm{Na}$ modernidade, surgem dois sentidos, ou duas condições, da experiência: o primeiro sentido coloca-a o mais para fora possível do sujeito, no experimento, e o segundo sentido, o mais para dentro do sujeito, no uso da razão que independe da ação do exterior. Apesar da diferença de estratégia na elaboração de critérios, ambos os sentidos têm como pretensão a identidade e a universalidade do conhecimento. De um lado, a "experiência" legitima-se no experimento que tem como característica ser controlado, homegeneizado, calculado, para se encontrar a objetividade e a repetibilidade do experimento, cujo resultado seria um conhecimento universal e necessário, conforme uma matriz idealizada por Bacon (1620). Por outro lado, tem-se a filosofia racionalista que procura cercear a validade da experiência externa como valor de verdade, resguardando ao uso da razão essa função, conforme uma matriz cartesiana (1637 e 1641) ${ }^{3}$.

A partir disso, surgem dois modos de nos relacionarmos com o mundo, ou seja, dois modos de nos relacionarmos com a cultura. No entanto, tanto de uma vertente quanto de outra, o que está em jogo é a busca por critérios de verdade tendo por objetivo a criação de uma cultura da verdade. Nesse sentido, concordamos com Larrosa ao afirmar que: "nos modos de racionalidade dominante, não há logos da experiência, não há razão da experiência, não há linguagem da experiência, por mais que essas formas de racionalidade façam uso e abuso da palavra experiência" (LARROSA, 2004, p. 22).

Esses critérios de validação científicos e filosóficos passaram a ser os legítimos instrumentos que o indivíduo deveria usar para avaliar e se integrar à vida cultural. Nesse sentido, eles corroboraram a busca de uma homogeneização cultural, uma vez que esta também precisaria ser submetida aos critérios científicos e filosóficos que buscam a universalização daquilo que se conhece. Assim, tornamo-nos mais pobres nas experiências culturais que têm como característica não a universalidade das ideias, mas a fugacidade, a heteronomia, a mutabilidade, a concretude das relações pessoais e a particularidade dos contextos em que as experiências culturais nascem, constituem-se e desenvolvem os vínculos afetivos.

O ensino da filosofia pautou-se nesses critérios científicos e filosóficos cujo mote não é a valorização da cultura particular de um povo, mas a cultura geral e universal produzida pelos grandes eruditos. A filosofia, ao corroborar o empobrecimento da experiência, contribuiu para o enfraquecimento dos modos de vida das pessoas e em seu lugar colocou 
um modo de vida que não lhe é próprio. Superior? Talvez. Mas sem sentido para aqueles que não estão dispostos a serem filósofos ou eruditos. Assim, em vez de criar um lugar de resistência a esse empobrecimento cultural e ao empobrecimento da vida, resistência que poderia ser um lugar de potencialização da cultura e da vida, corroboram seu incremento, transformando a cultura e a vida em uma mortalha.

\section{Resistir ao instituído: o lugar do ensino da filosofia}

A pergunta que nos fazemos é a seguinte: é possível que o ensino da filosofia, tão defendido e polemizado nos dias atuais, no Brasil, com as atuais conquistas alcançadas por seu retorno ao ensino médio, possa ser e servir como uma política de resistência ao empobrecimento cultural que vivemos? A resposta poderia ser afirmativa, desde que se mudasse o modo de encarar seu ensino; desde que ele não fosse mais um lugar onde os modos de vida das pessoas fossem desconsiderados; desde que ele não funcionasse como um lugar de reduto da transmissão dos "verdadeiros valores culturais". Então, como pensar um ensino da filosofia que cumpra esse papel político-cultural?

Gostaríamos de propor aqui uma das várias possibilidades de se pensar esse ensino da filosofia que já foram enunciadas, mas esquecidas no decorrer da história. Um dos filósofos que pode ser considerado um marco na história do pensamento sobre o ensino da filosofia é Nietzsche. A importância desse filósofo está na crítica feita por ele a Kant e a Hegel em sua concepção de filosofia e, consequentemente, no modo como entende ser o ensino da filosofia na sua relação com a cultura, principalmente por colocar em xeque a concepção mesma de filosofia desses autores e do modo de pensar a filosofia de sua época.

As principais correntes filosóficas com as quais Nietzsche dialoga são a de Kant, e as de fundamentação kantiana, e a de Hegel, que elege como seu principal interlocutor ${ }^{4}$. $\mathrm{O}$ estilo de filosofar naquele momento, principalmente no ensino da filosofia, era o de ensinar a filosofar, tendo em vista a formação do sujeito de cunho kantiano que buscava potencializar aquilo que o homem tinha como natural, o uso da razão, e um ensino da história da filosofia como condição impreterível para o filosofar, 
proposta pela filosofia da história hegeliana. Tanto Kant quanto Hegel valorizam a busca pela verdade e, podemos dizer, da verdade do ensino da filosofia como caminho para a culturalização do homem. Esse é o lugar no qual Nietzsche vai centrar sua crítica a esses filósofos, questionando a possibilidade de se alcançar a verdade, seja sobre valores, sobre o conhecimento das coisas ou ainda sobre a cultura a partir da qual todos deveriam ser educados.

Nietzsche inaugura, assim, outro modo de fazer filosofia, que escapa das propostas do aprender a filosofar pelo uso correto da razão kantiano e do ensino da história da filosofia e da humanidade para se integrar ao espírito objetivo do tempo forjado por Hegel. A proposta nietzscheana de filosofar se dá pela intempestividade do pensamento e como crítica a todos os valores que se impõem ao pensamento e à cultura e, principalmente, na aceitação de qualquer valor social, filosófico ou religioso como tendo em si um valor de verdade. Nietzsche questiona a educação de seu tempo por estar muito mais fundada na repetição dos valores morais e da moralização dos valores sobre a verdade, do que pela criação, pela contestação ou pela crítica a eles. Podemos encontrar essa problematização no seguinte fragmento: "Vive-se de fato do capital de moralidade acumulado por nossos ancestrais e da herança deles, que não sabemos mais fazer crescer, mas somente dissipar" (NIETZSCHE, 2003, p. 145). Para Nietzsche, a impotência do pensamento diante dos valores faz com que passemos a ser apenas cordeiros no rebanho cujo pastor é a verdade abstrata ou deificada pela cultura, pela tradição ou até mesmo pela religião. Assim, a ausência de um pensamento capaz de ser forte o suficiente para libertar o pensar desse vínculo à tradição cultural fez com que o ensino se desse pela pura repetição, formalidade e abstração do conhecimento, o que levou Nietzsche a questionar a própria possibilidade em se ensinar a filosofia nos moldes correntes. Segundo Nietzsche, a formação objetiva visa a

[...] imobilizar este instinto filosófico natural por meio do que se chama agora de 'cultura histórica' [Historische Bildung]. Um sistema que até pouco tempo atrás gozava de uma celebridade mundial escandalosa encontrou a fórmula da autodestruição da filosofia. (NIETZSCHE, 2004, p. 128).

Nietzsche propõe uma revisão do modo de fazer filosofia e, consequentemente, de ensinar a filosofia que desconsiderava algo que, para ele, era de fundamental importância: a vida, para colocar em seu lugar o 
uso da Razão ou o Espírito Absoluto, detentores da verdade e da verdadeira racionalidade filosófica e cultural. Nietzsche quer resgatar a vida viva que fora desprovida de sentido e substituída por outra vida abstrata e metafísica, transvalorá-la e colocá-la como ponto central do seu filosofar e do ensinar a filosofia. Assim, o sentido da filosofia, para Nietzsche, está na crítica da cultura e do Estado ou de qualquer ordem civil instituída; para ele, essas seriam as mortalhas que submetem o homem e retiram dele aquilo que lhe é próprio: a vida.

Essa proposta de filosofia pode ser encontrada em toda a obra de Nietzsche, mas é colocada de forma bem contundente em O livro do filósofo, momento em que se pergunta "O que deve fazer um filósofo?" (NIETZSCHE, 1984, p. 25). Poder-se-ia interpretar essa questão como sendo relativa ao dever moral, no entanto, se assim fosse, imprimiríamos a ela um caráter deontológico metafísico e deslocaríamos a vida do lugar privilegiado em que Nietzsche quer colocá-la. Por isso, ele modifica o modo de perguntar e não se questiona mais sobre os valores eternos que "devem reger" o comportamento cultural, mas sobre o valor existencial que norteia a cultura, trazendo a vida para dentro do próprio problema. A resposta que Nietzsche nos apresenta é a seguinte: "O valor da filosofia nesta satisfação não diz respeito à esfera do conhecimento, mas à esfera da vida" (NIETZSCHE, 1984, p. 34). Com isso, muda o foco, o objeto e até mesmo o modo de fazer filosofia no seu tempo, retirando o problema do conhecimento de seu status, marcado principalmente por Kant e por Hegel, e colocando a vida, desprovida de sentido metafísico, como principal objeto do pensamento filosófico, com o objetivo de transvalorá-la.

A consequência dessa mudança afeta diretamente a compreensão de cultura e de formação tão cara ao ensino da filosofia, deixando de ter como objetivo o preparo do espírito ou o preparo para o ingresso na Cultura, em Kant e Hegel, e passando a ser uma Bildung da cultura para a vida, na qual notamos claramente a destinação da formação cultural, que antes se dava para o geral e que, com Nietzsche, se volta para a singularidade do humano. Assim, para Nietzsche, o ensino da filosofia precisaria se dar na problematização da vida humana em sua relação consigo mesma e em relação com a sociedade, como uma crítica do tempo presente e dos modos como a vida se efetiva nessas relações.

A formação cultural, então, não poderia mais se dar na formação para a cultura e sim na formação da vida e para a vida. Ela consistiria em 
desaprender a própria cultura, que fora imposta, para se criar outra cultura (contracultura), que não seria mais universal e necessária, mas imanente e singular, tendo como lugar de tensão a própria vida. Assim, o ensino da filosofia precisaria se pautar na crítica aos valores e à universalização culturais, bem como na criação do gênio como crítico de seu próprio tempo. Isso porque, para Nietzsche, "Um povo que se torna consciente dos perigos [que a cultura lhe impõe] produz o gênio" (NIETZSCHE, 1984, p. 23), que é capaz de produzir uma contracultura como "odioso destruidor da civilização nacional” baseada em valores, leis e conhecimentos que estão fora da vida.

Nietzsche traz o filósofo como médico da sociedade que precisa de tratamento. Porém, o médico não é aquele que construirá a nova sociedade, mas aquele que poderá propiciar, oferecer um tratamento para que ela seja capaz de se curar. Isso porque, para ele,

Não existe na natureza criatura mais sinistra e mais repugnante do que o homem que foi despojado do seu próprio gênio e que se extravia agora a torto e a direito, em todas as direções. Afinal, não se tem mesmo o direito de atacar um tal homem, pois ele existe somente fora do eixo, como fantasia frouxa, tingida e gasta, como um espectro sarapintado que não pode inspirar medo e menos ainda compaixão. E mesmo que se diga, com razão, do preguiçoso que ele mata o tempo, será preciso também ocupar-se seriamente, de uma vez para sempre, com matar o tempo de uma época que coloca sua salvação nas opiniões recebidas, quer dizer, nos vícios privados; em outras palavras, é preciso apagar este tempo da história da autêntica emancipação da vida (NIETZSCHE, 2004, p. 139).

Por isso, é preciso envenenar as bases nas quais está fundada a cultura, ou seja, envenenar a doença que causa o mal estar na civilização para destituir a dominação que a fere e a domina. A função do filósofo é, então, envenenar as verdades que servem de fundamentação da cultura, envenenar os valores que a constituem e ferir de morte a doença social que a inibe de progredir em sua natureza. Senão, "Qual não seria a aversão das gerações futuras, quando tivessem de se ocupar com a herança deste período, em que não são os homens vigorosos que governam, mas os arremedos de homem, os intérpretes da opinião" (NIETZSCHE, 2004, p. 139). Para Nietzsche, se o homem não escapar dessas mazelas nas quais a cultura o coloca, não passará de um animal domesticado ou em vias de domesticação. 


\section{A experiência e a vida}

A partir do exposto, podemos dizer que Nietzsche é um homem de seu tempo, que pensa seu presente e faz a crítica tanto aos pensadores quanto àqueles que influenciam o pensamento na constituição da cultura de seu presente. A pergunta que agencia e potencializa esse modo de pensamento é a seguinte: O que estamos fazendo de nós mesmos? A resposta à questão poderia, então, ser: estamos colocando a vida viva (bíos) como motivadora e potencializadora do pensamento, da filosofia e, consequentemente, de qualquer política cultural. Para Nietzsche, a própria colocação do problema da filosofia nesses termos retiraria o pensamento de seu lugar moralizante ou do modo moral de pensamento.

Podemos dizer, então, que, para Nietzsche, o ensino da filosofia que não estiver marcado pela própria vida como valor transvalorado do pensamento que é a própria vida viva seria apenas uma reprodução da cultura estabelecida, que impediria o nascimento do gênio capaz de problematizar aquilo que precisa ser questionado na cultura empobrecida e empobrecedora em que ele vivia (e, podemos dizer, que nós vivemos). Para isso, o ensino da filosofia precisaria se dar como uma experiência de pensar e não como um vínculo às regras e às objetividades capazes de produzir um pensamento verdadeiro.

Para que isso se efetive, precisamos pensar esses restos, ou seja, pensar aquilo que afeta nossa vida; pensar aquilo em que estamos ligados; pensar aquilo que está ligado à nossa própria experiência e que sequestra nosso pensamento. Então, pensar nossa própria existência pode ter algum sentido se entendido como uma atitude de resistência, sobretudo em uma época em que perguntar-se sobre o que fazemos de nós mesmos parece soar estranho. Nesse sentido, parece-nos que a atitude a se tomar é a de resistência à ausência de pensamento sobre si mesmo, de pensamento sobre uma ética de si mesmo e da existência. Por isso, o que urge é uma atitude de resistência aos processos de sujeição do pensamento nos quais estamos envoltos. Resistir ao empobrecimento da experiência de nós mesmos e recuperar os restos que sobraram desse sujeito ainda capaz de resistir.

Sobre esse lugar de ausência e resistência, podemos pensar o que fazer. Melhor dizendo, podemos nos produzir a nós mesmos na ausência de algo que nos guie e iniciar uma invenção de nós mesmos em que o cui- 
dado com a própria vida seja priorizado. Assim, com a atitude de cuidar, somos lançados a pensar de tal modo a fazermos uma ontologia de nós mesmos, ou seja, lançarmo-nos aos problemas a serem pensados e que emergem daquilo que foi expulso/silenciado com o empobrecimento da experiência: a vida e a experiência dessa vida viva.

\section{Notas}

${ }^{1}$ Vale destacar aqui a mais recente conquista dos professores de Filosofia: o retorno da Filosofia nas séries do ensino médio. Porém, as faculdades e institutos de ensino superior vêm gradativamente retirando as disciplinas de Introdução à Filosofia, Filosofia da Educação e Filosofia e Ética Fundamental de seus currículos escolares. A justificativa para isso recai no argumento de que há uma exigência de apressamento na formação do aluno universitário pela demanda do mercado e que, por isso, disciplinas que não contribuam diretamente com a formação profissional precisam ser eliminadas do currículo. Outro argumento que ampara a supressão da Filosofia nesses cursos é a necessidade de que as disciplinas "menos necessárias" deem lugar àquelas de "fundamental importância" à formação técnica. A título de exemplo, os cursos de Pedagogia que tinham suas disciplinas divididas ao longo de quatro anos, atualmente são realizados em apenas três anos, em boa parte das faculdades. Poderíamos imputar a razão disso simultaneamente à pressa das instituições privadas em formar os alunos para obter maior lucro com sua formação e à pressa dos próprios alunos para entrar no mercado de trabalho o mais rapidamente possível. No entanto, notamos que mesmo as instituições de ensino público estão seguindo um caminho muito parecido, descartando de seus currículos a disciplina de Filosofia e, em alguns casos, inclusive a de Filosofia da Educação. Para nos determos a apenas um exemplo desse fato, podemos fazer referência à recente retirada da disciplina de Introdução à filosofia do curso de Pedagogia da UNESP de Marília, em 2006, sob alegação da necessidade de se criar espaço para "disciplinas imprescindíveis" à formação dos futuros pedagogos. Para maior aprofundamento dessa questão, ver a discussão apresentada por Gelamo (2009) sobre o lugar do ensino da Filosofia no ensino médio e nas faculdades, em sua tese de doutorado intitulada O problema do ensino da filosofia no limiar da contemporaneidade: o que faz o filósofo quando seu ofício é ser professor de filosofia?

${ }^{2}$ Vale ressaltar aqui que nosso objetivo não é atribuir à Filosofia a grande responsabilidade pela formação cultural do homem, nem mesmo atribuir à sua banalização o enfraquecimento da cultura na contemporaneidade. O que pretendemos, no entanto, é destacar que a Filosofia, como uma possível forma de se pensar a cultura, está passando por problemas.

${ }^{3}$ Nosso objetivo aqui não é fazer um longo resgate de como a experiência foi tratada no decorrer da história da filosofia, mas pontuar algumas formas como ela foi tratada. Para maior aprofundamento dessa problemática, ver Gadamer (2002), Jay (2002; 2005), Agamben (2005), Larrosa (2004), Bárcena (2005), Morey (2007) e Gelamo (2009). 
${ }^{4}$ Vale ressaltar que Nietzsche combate fortemente a filosofia nascente de Augusto Comte, principalmente em Além do Bem e do Mal (2005). No entanto, essa crítica não será objeto de nosso estudo, dada a limitação que nos propomos aqui, que é o ensino da Filosofia.

\section{Referências bibliográficas}

AGAMBEN, G. Infância e História: destruição da experiência e origem da história. Belo Horizonte: Editora da UFMG, 2005.

AGAMBEN, G. Homo sacer: o poder soberano e a vida nua I. Belo Horizonte: Editora da UFMG, 2004.

BACON, F. (1620). Novum Organum ou Verdadeiras interpretacões acerca da natureza. São Paulo: Nova Cultural, 1999.

BÁRCENA, F. La experiencia reflexiva en educación. Barcelona: Paidós, 2005.

DESCARTES, R. (1637) Discurso do Método. In: Descartes: coleção os pensadores. São Paulo: Nova cultural. 1999. p. 33-100.

DESCARTES, R. (1641) Meditações. In: Descartes: coleção os pensadores. São Paulo: Nova cultural. 1999. p. 233-334.

FOUCAULT, M. Dits et écrits:1954-1988. Organizado por Daniel Defert e François Edward. Paris: Galimard, 1994. 2v.

FOUCAULT, M. O que é a crítica?. In. Cadernos da F.F.C. Organizado por BIROLI, F.; ALVAREZ, M. C. Marília: Unesp-Marília-Publicações, 2000, v. 9, n. 1. p. 169-189.

FOUCAULT, M. História da sexualidade: o uso dos prazeres. 10 ed. Rio de Janeiro: Graal, 2003, v. 2.

FOUCAULT, M. A Hermenêutica do sujeito. São Paulo: Martins Fontes, 2004a.

FOUCAULT, M. A ordem do discurso. 11 ed. São Paulo: Edições Loyola, 2004b.

GADAMER, H. G. Verdade e método. Rio de Janeiro: Vozes, 2002.

GELAMO, R. P. O problema do ensino da filosofia no limiar da contemporaneidade: o que faz o filósofo quando seu ofício é ser professor de filosofia? São Paulo, Cultura Acadêmica, 2009. Disponível em:

http://www.culturaacademica.com.br/downloads/\%7BDE44A0D1-1710-4F9B-B0F8347111101111\%D_Ensino_da_filosofia_limiar_da_contemp-NOVA\%20P4.pdf

HEGEL, F. Escritos pedagógicos. México: Fondo de Cultura Econômica, 1991.

HEGEL, F. Discurso sobre educação. Lisboa: Edições Colibri, 1994.

JAY, M. La crisis de la experiencia en la era pos-subjetiva. Prismas, revista de historia intelectual. n. 6, p. 9-20, 2002.

JAY, M. Songs of experience: modern American and European variations on a universal theme. Berkeley and Los Angeles: University of California Press. 2005.

KANT, I. (1784) Que é o esclarecimento? (Aufkalärung). In: CARNEIRO LEÃO, E. (org). Immanuel Kant: Textos seletos. Petrópolis: Vozes, 1985.

KANT, I. (1787) Crítica da Raẓão Pura. Lisboa: Fundação Kalouste Gulbenkian, 1989.

KANT, I. (1789) O Conflito das faculdades. Lisboa. Edições 70, 1993.

KANT, I. Sobre a pedagogia. Piracicaba: Editora da Unimep, 1996.

LARROSA, J. Algunas notas sobre la experiencia y sus lenguajes. In: Trajetórias e perspectivas da formação de educadores. São Paulo: Editora da Unesp: 2004. p. 19-34. 
NIETZSCHE, F. (1886) Além do bem e do mal. São Paulo: Companhia de Bolso, 2005.

NIETZSCHE, F. Genealogia da moral: uma polêmica. São Paulo: Companhia das Letras. 1998.

NIETZSCHE, F. Escritos sobre educação. 2 ed. Rio de Janeiro: Loyola, PUC-Rio, 2004.

NOVELLI, Pedro Geraldo Aparecido. O ensino da filosofia segundo Hegel: contribuições para a atualidade. Trans/Form/Ação, Marília, v. 28, n. 2, 2005.

PELBART, P. P. Vida nua, vida besta, uma vida. Disponível em <http://p.php.uol.com.br/tropico/html/textos/2792,1.shl>. Acesso em 22/7/2007.

PAGNI, P. A. Os limites e as discretas esperanças do ensino de filosofia. In: GALLO, S; DANELON, M; CORNELLI, G. Ensino de Filosofia: Ensino e Prática. Ijuí: Editora Unijuí. 2004. p. 217-263.

Endereço para correspondência: Universidade Estadual Paulista Júlio de Mesquita Filho Faculdade de Filosofia e Ciências Rua Higino Muzzi Filho, 737

Cidade Universitária

CP 181

79117-900

Marília - SP

Data de recebimento: $02 / 03 / 2009$

Data de aprovação: 14/01/2010 